\title{
Article \\ Design and Simulation of Manufacturing Organizations Based on a Novel Function-Based Concept
}

\author{
Mareike Winkler $^{1}$, Sergio Gallego-García ${ }^{2, * \mathbb{C}}$ and Manuel García-García ${ }^{3}$ \\ 1 Institute for Social Sciences, University of Oldenburg, 26129 Oldenburg, Germany; \\ mareike.winkler@uni-oldenburg.de \\ 2 Industrial Engineering Technologies of the International School of Doctorate, National Distance Education \\ University (UNED), 28040 Madrid, Spain \\ 3 Department of Construction and Fabrication Engineering, National Distance Education University (UNED), \\ 28040 Madrid, Spain; mggarcia@ind.uned.es \\ * Correspondence: sgallego118@alumno.uned.es; Tel.: +34-682-880-591
}

check for updates

Citation: Winkler, M.; Gallego-García, S.; García-García, M. Design and Simulation of Manufacturing Organizations Based on a Novel Function-Based Concept. Appl. Sci. 2022, 12, 811. https://doi.org/ 10.3390/app12020811

Academic Editor: Antonella Petrillo

Received: 26 November 2021

Accepted: 4 January 2022

Published: 13 January 2022

Publisher's Note: MDPI stays neutral with regard to jurisdictional claims in published maps and institutional affiliations.

Copyright: (c) 2022 by the authors. Licensee MDPI, Basel, Switzerland. This article is an open access article distributed under the terms and conditions of the Creative Commons Attribution (CC BY) license (https:// creativecommons.org/licenses/by/ $4.0 /)$.
Featured Application: Modeling manufacturing organizations for optimizing their design, management, control, and continuous improvement by considering all functions and their assignment to specific areas and employees enabling the identification of improvement potentials.

\begin{abstract}
Historically, researchers and managers have often failed to consider organizations as a sum of functions leading to a set of capabilities that produce a product that can serve society's needs. Furthermore, functions have increased with the development of industrial revolutions, however, many manufacturing organizations have not realized their full potential. As a result, many industrial organizations do not know why, where, and when the existing functions and projects for implementing new functions fail where tactical and strategic functions of a manufacturing organization are commonly over-seen. Thus, the aim of this research was to propose a holistic approach for manufacturing organizations in order to model their functions enabling the assessment, design, management, and control of operations and performance as well as to identify improvement potentials. For this purpose, a conceptual model was developed based on the evolution of functions along with the industrial revolutions. Moreover, using the conceptual model, manufacturing organizations can be modeled, considering common organizational functions in the respective areas of production, maintenance, and quality, etc., in the three planning horizons—strategic, tactical, and operative. As a result, the model serves as a basis for the integral management and control of manufacturing organizations. Moreover, it can be also used as a basis framework for a digital twin model for organizations. Thus, a system dynamics simulation model based on the conceptual model was developed for a generic organization. The goal of the simulation model is to provide an exemplary digital model of a manufacturing organization in which the different functions are applied with different methods, systems, and/or individuals along the development phases.
\end{abstract}

Keywords: organizational modeling; manufacturing management and control; quality management; maintenance management; supply chain management; human factor; system dynamics; simulation; digital twin; Industry 4.0

\section{Introduction}

Human society seeks a progressive improvement in quality of life, and industry has contributed to achieving this goal via the industrial revolutions [1]. Since the first industrial revolution, subsequent revolutions have resulted in manufacturing advances with processes that are increasingly complicated, automated, and sustainable in which machines are operated simply, efficiently, and continuously [2]. Self-optimization as a basic principle serves as an approach to handle complexity and unforeseen disturbances within 
supply chains, machines, and processes [3]. However, the standards for smart factory implementation have not yet been established [4].

Modern manufacturing plays an essential role in the world, especially in European countries. About $17 \%$ of the GDP (gross domestic product) is accounted for by industry, which also creates approximately 32 million jobs with several supplementary occupations in the European Union [5]. However, in recent years, the industries of European countries have been facing many problems, such as an aging population and competition from developing countries [5]. These problems have driven the development of industrial technologies for reducing the labor force, shorting the developing time of the product, using resources efficiently, etc., of which the cyber-physical system (CPS) and Internet of Things (IoT) are two state-of-the-art technologies that have advanced within the last decade [5]. The research of key technologies not only refers to the integration of information technology as the main body but also includes the traditional disciplines such as control theory, mechanical technology, and materials and energy [4]. In this context, the goal of the fourth industrial revolution is to achieve real-time interconnection, mutual recognition, and effective communication between humans, equipment, and products, and eventually to build a highly flexible and personalized smart manufacturing environment [6].

In particular, it emerged that the relevance of digital twins (DTs) for the manufacturing industry lies in their definition as virtual counterparts of physical devices. This allows their representation to reflect the current status of the system and to perform optimizations [7]. A gap in current manufacturing is that it has not reached an Industry 4.0 level comprehensively although many researchers and companies are working on this topic. All current manufacturing systems are able to cover some Industry 4.0 concepts, concentrated mainly in interoperability [8]. Therefore, there is still a long way to go to improve manufacturing up to the required level [5].

The fusion of the physical world and the cyber world creates a new form of production systems-CPSs [6]. CPSs are considered next-generation smart systems that integrate computing, communication, and control technologies. In this way, CPSs enable close interactions between the cyber and physical components through human-computer interaction interfaces [6]. By means of virtualization, companies are able to monitor physical processes and develop simulation models [9]. In this context, real-time information available for organizational tasks is key to tracking and analyzing the status of the manufacturing organization supporting to increase the robustness to unexpected conditions [9]. However, there are some challenges and fundamental issues during the implementation of Industry 4.0 in the current manufacturing industries such as system modeling and analysis [2]. The joint effect of decisions belonging to various production areas which are traditionally considered in isolation, such as logistics, maintenance, and quality, is difficult to predict. DTs are particularly relevant when integrated into process control loops, as presented in for process quality improvement [10].

Although much research work has already been conducted in the field of production management, manufacturing companies still face massive challenges deriving from unexpected failures. To enable manufacturing companies to process the increasing data gathered, useable models providing sustainable solution alternatives must be developed [11]. Until recently, there has been no modeling method or methodology which can be used to model, analyze, and design complex manufacturing systems completely or support most phases of these complex systems. Most available modeling methods are simply static graphical representations and are not well defined. Modeling requires a method that is simple and able to support different levels of abstraction. Analysts and designers need to model basic manufacturing operations as well as relevant management decisions and information systems. Most authors agree that no one technique can model the functional, information, dynamic behavior, and decision aspects of systems [12]. Furthermore, at the moment of writing this paper, no function-based concept has been published for modeling manufacturing organizations. As a result, the novelty of the paper relies on the development of a function-based model for manufacturing organizations. Moreover, the conceptual model 
develops its application for the identification of improvement potentials and for the diagnosis of malfunctions based on failure mode and effect analysis (FMEA) for manufacturing functional areas. Furthermore, the model enables its application as a digital model by simulating the different functional developments over history.

In this context, historically, researchers and practitioners have often failed to consider organizations as a sum of functions leading to a set of capabilities that produce a product that can serve society's needs. Furthermore, functions have increased with the development of industrial revolutions. This has occurred in all areas from technical manufacturing processes to maintenance management passing by quality and logistics management. Although possibilities to enhance functions as well as to increase their effectiveness, efficiency, and scope have developed over time, many manufacturing organizations have not realized their potential, as can be explained when new companies overplay existing players in relatively short-time periods as they are able to utilize all the new functions available enabling greater competitiveness in global markets. As a result, many industrial organizations do not know why, where, and when the existing functions and projects for implementing new functions fail.

Moreover, with the advent of Industry 4.0, the connection of the physical and digital world has led to cyber-physical systems and digital twins. However, in most cases, the focus of these research and practical applications relies on the operative levels of the main functions of manufacturing organizations, i.e., manufacturing process, maintenance monitoring, quality control for products, and processes. In this context, the tactical and strategic functions of a manufacturing organization are commonly overseen. Thus, the aim of this research was to propose a holistic approach for manufacturing organizations in order to model their functions enabling the assessment of the organization's performance and identifying improvement potentials. For this purpose, a conceptual model was developed based on the evolution of functions along with the industrial revolutions in order to identify an integral generic set of functions relevant to the assessment of any manufacturing organization. Moreover, using the conceptual model, manufacturing organizations can be modeled, considering all common organizational functions in the respective areas of production, maintenance, and quality, etc., in the three planning horizons-strategic, tactical, and operative. As a result, the models serve as a basis for the integral management and control of manufacturing organizations, since they can be applied for the design, management, and control of operations as well as for identifying and quantifying potential improvements. Thus, a system dynamics simulation model based on the conceptual model is developed for a generic manufacturing organization. The goal of the simulation model is to provide an exemplary digital model of a manufacturing organization in which the different functions are applied with different methods, systems, and/or individuals. Finally, the paper provides a novel modeling method for manufacturing organizations with a fundamental contribution for optimizing their design, management, control, and continuous improvement based on a hybrid conceptual-practical approach by considering all functions within manufacturing organizations as well as their assignment to specific individuals within the organization enabling the identification of improvement potentials in the management, technical, or staff areas.

\section{Methodology, Fundamentals, and Materials}

\subsection{Methodology}

In this paper, the methodological approach is as follows:

- Literature research on the manufacturing process, production systems, quality management and control, maintenance management, logistics management, information systems, the human factor, system dynamics, simulation, and the integrated functionbased manufacturing organizational model.

- Function development over history with a focus on seven functional areas: manufacturing processes and technologies, production planning system, quality, maintenance, logistics, information systems, and human resources. 
- Development of a conceptual model as an integrated model with the goal of serving as a framework for assessing the functional areas of a manufacturing organization enabling the continuous improvement to support the management, control, and decision making for managerial and technical positions within industrial organizations.

- Interpretation of results and derivation of implications and use cases for managers and technicians.

- Critical reflection of the research performed, and outlook of potential future research based on the findings of the paper.

\subsection{Functions Development during Industrial Revolutions}

The manufacturing industry profoundly impacts economic and societal progress [13]. Human society desires a progressive improvement of life quality. Industry has been advancing to keep pace with this kind of requirement. Furthermore, industry can continue to improve people's living standards by providing customized and high-quality products to consumers and setting up a better work environment for employees [1].

At the end of the 18th century, the first industrial revolution was witnessed with the introduction of mechanical production systems using water and steam power. This was followed at the beginning of the 20th century by the second industrial revolution with the introduction of mass production based on the division of labor with electrical energy [14]. Later, the third industrial revolution brought an increase in productivity through advanced electronics that increased calculation and storage capacities [3]. This began at the beginning of the 1970s due to the availability of electronics and IT for further centralized control of automation in production. As a result, industrial processes powered by electricity converted into standards and the use of sensors and gathering of data for monitoring of machine activity were initiated in the 1970s. Based on this capability of information exchange, the term "Industry 4.0" was introduced by representatives of business, politics, and academics gathered [13] that promoted the idea of digitization together with autonomy and self-behavior of machines as an approach to strengthening the competitive power of the German manufacturing industry [13]. Self-optimization is expected to improve the resilience and competitiveness of manufacturing companies [3]. The fourth wave is currently emerging with the use of cyber-physical systems. The Internet of Things and Services enables innovative, decentralized production processes for small batches and a significantly large number of product variants [14]. Industry 4.0 is based on the establishment of smart factories, smart products, and smart services embedded in an internet of things and of services also called the industrial internet [15]. Self-optimization can be regarded as the next step in control technology. Moreover, the cooperation of humans and technical systems requires a steady adaption of control structures. Therefore, selfoptimization is seen as a key enabler for the next level in order to increase productivity [3].

In the 1920s, quality was only seen as product quality. There was a separate department, "quality control", which carried out a final inspection task, followed by the classification of non-conforming parts. With progressive industrialization and the increase in mass production in the 1930s, control methods were developed for quality assurance such as statistical process control (SPC). Quality assurance became a production task. The goal was to avoid mistakes during the production process. In the 1960s, preventive methods such as FMEA or design reviews were developed. In this way, both the quality of the product and the quality of the process began to be considered. Quality was considered then from the development and with an interdisciplinary approach. However, the main focus of quality assurance was still on the technical sector. Total quality concepts that focus on customer requirements were developed in the 1990s. All employees and the business sector must be qualified to make the right decisions. Department thinking must be replaced by process thinking. Quality is seen as a strategic factor of competition. This new understanding of quality reflects the principles of quality management. Quality management is responsible for taking measures to guarantee quality throughout the company. Furthermore, while current systems are optimized toward a precise execution of a given 
set of parameters, self-optimizing systems need to be optimized toward product quality, and this can only be achieved if expert knowledge about the process and the boundary conditions is embedded [3].

Maintenance refers to all the actions that lead to the restoration of an item to its initial condition [16] in the most cost-effective way. Different maintenance strategies have emerged and evolved throughout history. The role of maintenance has emerged from mainly corrective maintenance activities to a key element for enabling process performance, availability, quality, and stability [17]. Maintenance is one of the most important activities during a products' lifecycle [16]. Throughout a product's lifecycle, maintenance consumes large amounts of time and financial resources. In order to minimize its effect, there is an effort towards integrating novel technologies that will facilitate relative technical knowledge distribution, even from remote locations [18]. Until the 1940s, corrective maintenance was predominant. Since the 1940s, the evolution of industrial maintenance can be explained in four stages. In the first stage of preventive maintenance [19], the breakdown and repair of machinery were regarded as necessary and not as costs with the potential to increase a company's profitability [20]. In the second stage, industrial maintenance planning and management systems were developed [19]. For this purpose, systematic studies on the service life of technical systems using statistics of failure intervals and duration were used [21] In the third stage, the "total productive maintenance (TPM) system" was established in 1969 with the transfer of routine maintenance procedures to machine operators [22]. In the fourth stage, presently, maintenance needs to go beyond keeping up with maintenance and ensuring availability [19]. In maintenance, the condition monitoring of machines has established itself as a remote service by continuously recording and analyzing the physical parameters of a machine. This allows potential errors to be identified early, avoiding machine failures [23]. Over the last decade, organizations have continuously increased their revenues from the service business, and they have begun to expand their business by offering product-related services. In particular, they offer maintenance, repair, and overhaul (MRO) services as well as technical support for their products, resulting in an increased importance of the service business for manufacturing organizations [24].

Over the last 50 years, a transition from the producers' market to the customers' markets has occurred [25]. During the 1950s and 1960s, each operation within each stage of the supply chain tried to minimize its own costs, which defined an intracompany intraoperation scope [26]. It was represented by the classic transport, transshipment, and storage (TTS) logistics, which looks for the optimization of delimitated functions [27]. In the 1970s, the scope was expanded including the optimization of cross-functional processes [28]. Moreover, quality problems came to the forefront of enterprise management and total quality management (TQM) was established [25]. The cost pressure already established in the 1980s - caused by the saturation of markets and an increasing competition situationcreated new quality and efficiency requirements on the enterprise process management [27]. Therefore, Kanban was implemented for controlling the material flow in production [28]. This period is also characterized by efforts for optimal inventory management and a reduction in production cycles [25]. At the end of the 1980s, the first cross companies' logistics concepts were developed. The introduction of the just-in-time (JIT) concept in the automobile industry and the efficient customer response (ECR) in trading are two examples of cross companies' logistics between supplier and producer and between producer and trader [28]. Later, in the 1980s and 1990s, companies were challenged by a high product variety and shortened time to market (TTM). Thus, the speed of reaction to the market arose as a critical factor with the purpose of cutting TTM [25]. However, it was in the 1990s when firms recognized the necessity of looking beyond the borders of their own firms to their suppliers, suppliers' suppliers, and customers to improve overall customer and consumer value. This movement, titled 'supply chain management' or 'demand chain management', shifted companies' focus from the internal management of business processes to managing across enterprises [29]. The development of SCM (supply chain management) was driven in the 1990 s by three main trends: customer orientation, markets globalization, and the 
establishment of an information society [25]. This led to a worldwide integration of value chains and to the optimization of global logistics networks in the 2000s [27].

In the 1960s, no company could afford to own a computer. Therefore, production and inventories were managed in such a way that there was adequate stock to satisfy the demand [30]. In this context, the origin of information techniques to support planning and production management control tasks began in the 1960s with the development of the concept of material requirements planning (MRP). As a complement to this closed consideration of materials and quantities, manufacturing resource planning (MRP II) was created in order to consider the capacities available within the company. With this development, specific manufacturing orders can be planned with their dates, production, and assembly batches as well as manufacturing processes associated with production capacities [31]. On this basis, the term 'production planning and control' (PPC) was coined in the early 1980s [32]. Luczak and Eversheim extended the PPC concept to include the entire technical order process from bid processing to product shipment [30]. The planning and control tasks affected the areas of sales, design, purchase, manufacture, assembly, and shipment of the product [33]. In the 1990s, the concept of MRP-II was extended to the concept of enterprise resource planning (ERP) incorporating all the functionalities of MRP-II and adding functionalities of finance, supply chain, human resources, and project management [30]. Today's information systems that support technical and commercial order processing tasks are known as enterprise resource planning (ERP) systems. The concept of ERP has been established for these entire enterprise information systems. Therefore, ERP systems are defined as integrated software solutions that consist of several modules, such as PPC, materials management, financial accounting, human resources, or logistics, and that interact through a central database [34].

Nowadays, among the main information systems, we find transactional management systems, logistics execution systems, planning and decision-making systems, and business intelligence systems [35]. On the other hand, ERP systems may have additional functionalities. The most common applications are [36]:

- PLM (product lifecycle management): product life management

- $\quad$ CRM (customer relationship management): customer management

- SCM: supply chain management

The manufacturing industry faces a growing quantity of data and this trend will continue to grow. Diversity and heterogeneity of data regarding, e.g., human, machine, and communication technologies are the greatest challenges for companies coming along with this development [11]. At top-level command and control, company management decisions are supported by ERP systems. Therefore, these systems allow the decision-makers in the management to monitor any enterprise-wide resources such as employees, machinery, or materials. At the lower levels, the manufacturing execution systems (MES), data acquisition (supervisory control and data acquisition, SCADA), and programmable logic controllers (PLC) are arranged according to the increasing complexity [37].

Throughout history, the human factor was first analyzed for management practices at the beginning of the twenty century after the experiences in the first industrial revolution. Moreover, during the second industrial revolution, the consideration of the human factor was introduced. Then, in the third industrial revolution, lean concepts were applied for the production system; in the current fourth industrial revolution, new technologies are enabling digital modeling, planning, and control of organizations.

\subsection{Materials and Methods}

The following sources, methods, and tools were used to perform the research:

- Modeling is the representation of a real-world scenario by a mathematical expression and/or a simplification of the real-world system. Simulation uses a model to generate data, and these data can then be analyzed [38]. Simulation allows companies to assess how decisions should be made and the optimal time to make them. Therefore, these analyses can assist in determining whether certain decisions are wise or not, acting 
as decision-supporting tools [39]. The use of simulation for manufacturing system design and analysis is recognized by scientists and industrial managers [40].

- System dynamics simulation: System dynamics is a method that was created in the mid-1950s by Professor Jay Forrester and is a method of studying dynamic systems. System dynamics suggests a very high abstraction level and is positioned as a strategic modeling methodology [41]. Simulations will be used more extensively in plant operations to leverage real-time data to mirror the physical world in a virtual model, which can include machines, products, and humans. Decision-making quality can be possibly improved by an easy and fast process with the help of simulations [2] Simulations thus become important and extremely efficient research methods in the current context of manufacturing digitalization. Applied in production systems, simulations can provide answers to how they respond to the various variables and unpredictable situations that arise. Simulation models are usually needed when it is impossible or quite difficult to develop an analytical solution to a studied problem [42]. This type of continuous simulation is chosen over discrete simulations, such as discreteevent or agent-based modeling, due to their high abstraction level that represents global causal dependencies with aggregates and feedback dynamics supporting the integral assessment and selection of strategic alternatives of a manufacturing system, while discrete simulations are focused on events or agents, that is, individual objects with exact sizes, timings, etc.; however, this is not the focus of the current study.

- Simulation software: The use of simulations for manufacturing systems design and analysis is rightfully recognized by scientists and industrial managers and the literature is abundant in this field [40] There are different software packages on the market that enable system dynamics modeling [43]. VENSIM (Ventana Systems) simulation software was selected for this research.

- Databases in Excel files were used as input data for simulations.

\section{Design of a Function-Based Model for the Identification of Improvement Potentials}

Modeling is an important tool for the investigation of complex problems [44]. The modeling, analysis, and design of manufacturing systems are difficult and complex tasks for many reasons [12]. In this context, in practice, partial models are still dominant; these models consider the process elements used and implemented in the first two industrial revolutions but lack the consideration of other functional elements.

\subsection{Design of a Function-Based Conceptual Model for Manufacturing Organizations}

The purpose of this study is to develop a conceptual model based on the historical development of manufacturing functions. In this context, since the beginning of the first industrial revolution, the means for producing goods have evolved continuously over time. Along with the technological development, other functional areas have been recognized as innovation fields, thus, improving their effectiveness and efficiency as well as expanding their scopes over time, from an execution-oriented focus in the operative levels to the coverage of strategic, tactical, and operative functions and tasks. However, this expansion of functions has not been homogeneous and parallel. On the other hand, it has been a sequence of developments motivated by previously generated needs, problems, or challenges. For instance, before mechanization occurred, there was no need to maintain or repair machines. Therefore, the use of machines for industrial production generated the need to maintain installations, thus, this function was developed. In the same way, other functions were developed as the need for managing and tracking individuals in concentration camp networks created the need for the use of IBM (International Business Machines) punch card tabulation machines, which were ancestors of the computer [45] opening a research line for inventory control that has converged in the computers, information technology (IT) systems, and ERP of our time. Based on the above-mentioned arguments, Figure 1 depicts the seven functional areas of a manufacturing organization with their evolution over time 
based on the main functional developments that have occurred in the past or are currently in place:

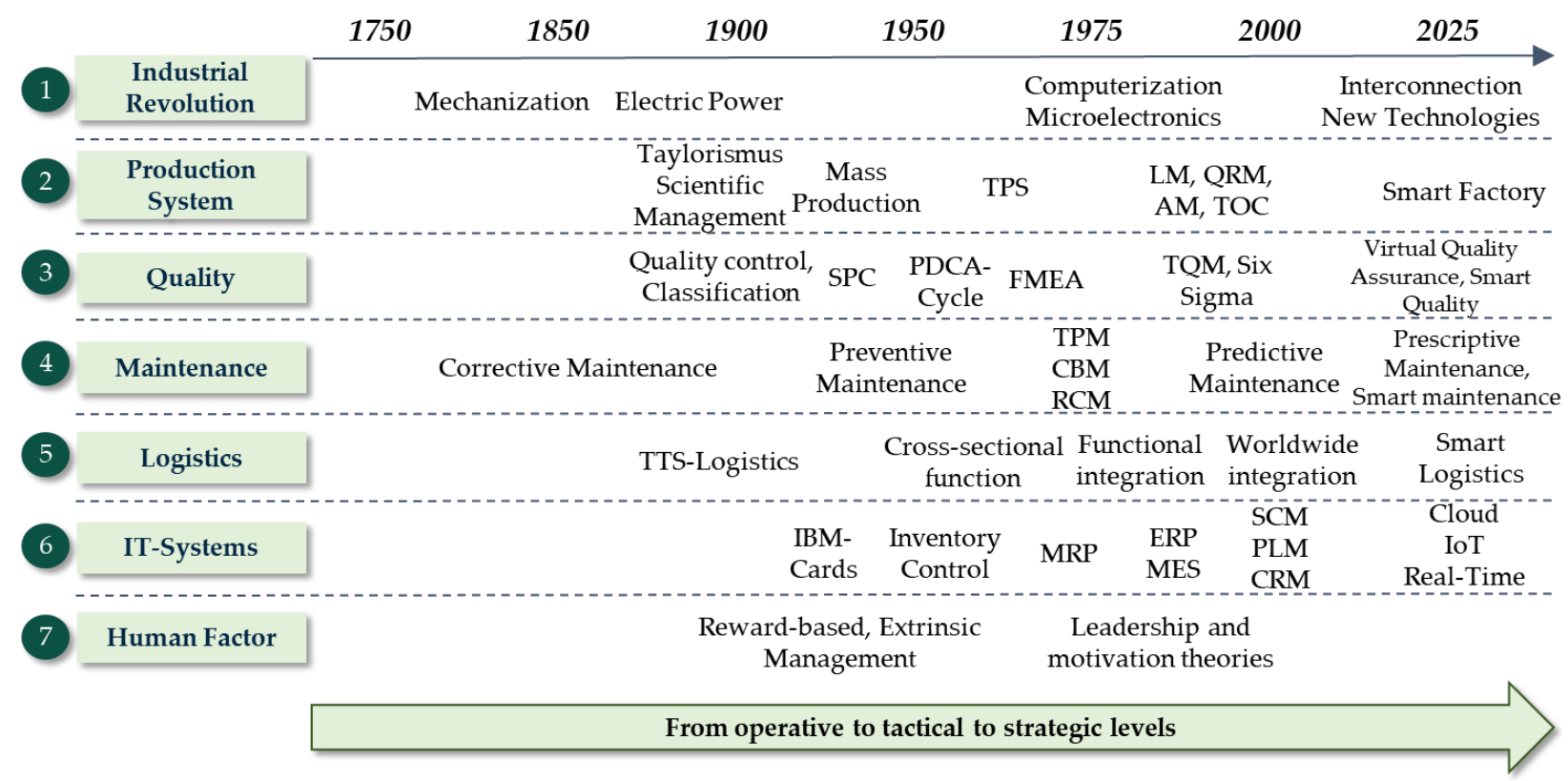

Legend: Toyota Production System (TPS), Lean Manufacturing (LM), Quick Response Manufacturing (QRM), Agile Manufacturing (AM), Theory of Constraints (TOC), Plan-Do-Check-Act (PDCA)-Cycle, Total Quality Management (TQM)

Figure 1. Function evolutions over time: seven manufacturing areas from operative to strategic levels (the authors' own elaboration).

From Figure 1, the development of the different functional areas can be observed in Figure 2, with the initiation by technology, followed by the production system change, later by quality and maintenance functional development, ending with the initiation of logistics, information systems, and human factor consideration. Moreover, based on Figure 2, different phases and clusters of the functional evolution within manufacturing organizations can also be derived, as shown in Figure 3. First, functional development was initiated by technology, i.e., mechanization. In a second step, as electric power made possible the production of larger volumes, the organization of the production system was developed with the scientific management of industrial production. Later, in a third step, although the production system was organized, managers identified the need for securing the technical limitations resulting from a lack of quality and availability. As a result, in this step, quality control and preventive maintenance functions were developed, as these functions were needed to secure market needs of mass production levels. In the fourth step, the logistics and systems functions were expanded thanks to the development of microelectronics and computers along with optimized forms of the production system organization as well as the support of new maintenance and quality concepts that also considered the strategic level. The logistics function developed from a TTS logistics function until the 1960s to the worldwide integration of value chains motivated by globalization at the beginning of the XXI century. Moreover, IT systems developed from a particular inventory control function to a complete set of systems integrating all vertical functions within the organization as well as all horizontal functions of the manufacturing supply chain. Finally, in a fifth step, the new technologies of the fourth industrial revolution are impacting the way in which the functions in all planning horizons are performed, opening the opportunity for higher efficiency levels, thanks to the smart factory, smart logistics, smart maintenance, smart quality within a cloud and IoT platform. 


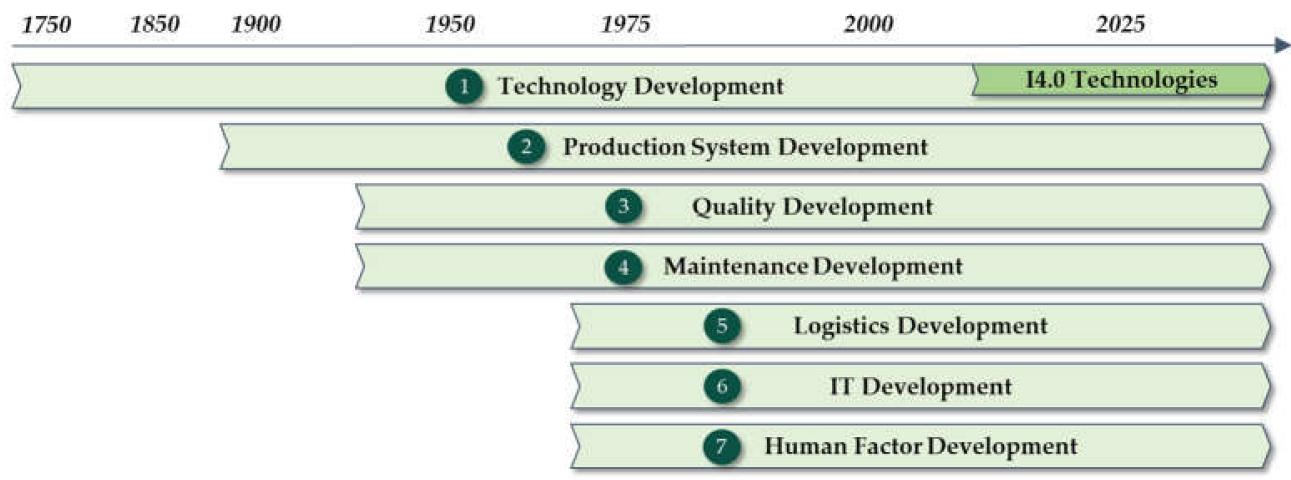

Figure 2. Functional Areas Development (the authors' own elaboration).

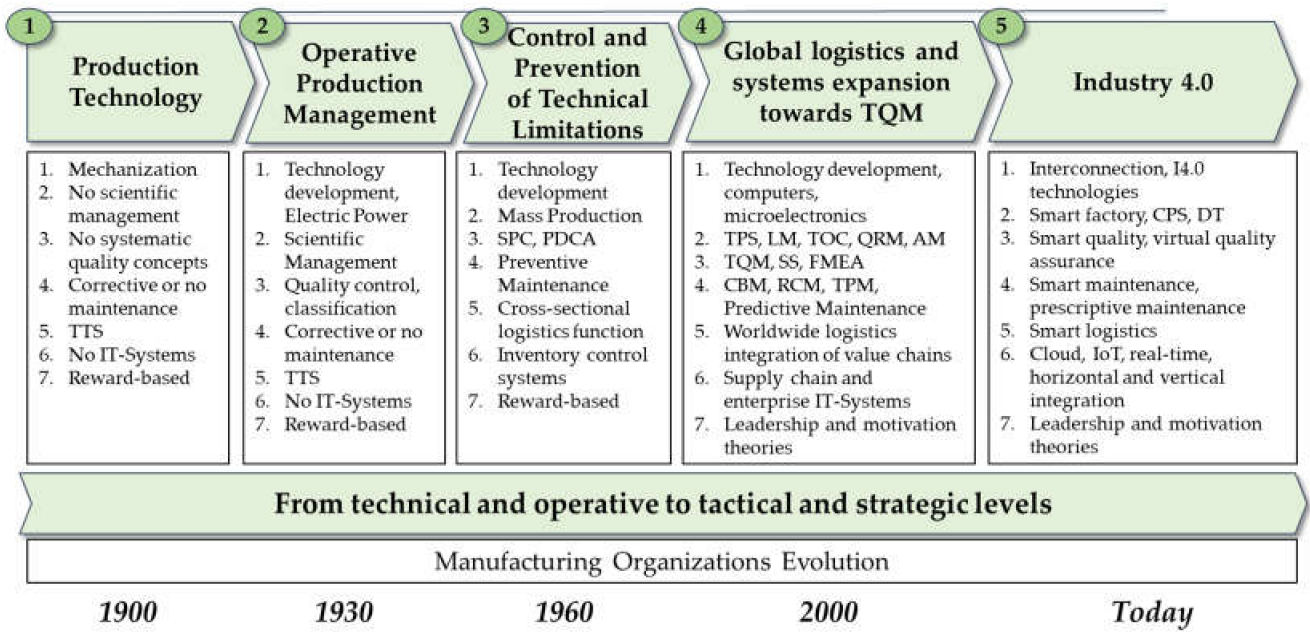

Figure 3. Manufacturing Function Development Phases and their characteristics (the authors' own elaboration).

\subsection{Identification of Functional Improvement Potentials}

This sub-chapter aims to identify improvement potentials in the functions for any manufacturing organization using a generic approach. It is performed by analyzing the adaptation level of each organization to the developments over the industrial revolutions, in particular before the third industrial revolution up to now. The conceptual model for a generic manufacturing process can be applied to the different levels of the network, plant, production line, machine group, and manufacturing element or cell, as represented by the recursion levels for existing capacity management models [46] and self-optimization frameworks for production systems $[3,47,48]$. The conceptual model of the current study enables a decision-making process based on the current system state in conjunction with the pursued goal, in which the level of abstraction correspondingly increases from the process level to the organizational level $[47,48]$. The system, therefore, requires human-machine interfaces that enable the operator to intervene if necessary. The optimization criteria of the production system and constraints are processed at each level and propagated to the next lower system [3].

Traditionally, manufacturing was limited to a process or a sequence of processes through which raw materials were converted into finished goods. However, the common understanding of manufacturing is considerably more complex. Manufacturing today considers the data-driven business in which smart manufacturing uses information to continuously maintain and improve performance [38]. Intelligent manufacturing began in the late 1980s, and the intelligent manufacturing system was developed in 1989 and founded in 1995; during this time, sensing, data processing, computing, communication, 
control, and other technologies had many limitations [6]. In this context, manufacturing organizations have been confronted by and will have to manage a growing quantity of data. For this reason, IT systems aim to support the management of processes and their interrelationships; however, the diversity and heterogeneity of data regarding, e.g., human, machine, and communication technologies, are a great challenge and a key factor for the success of the manufacturing industry [11]. An undersupply of this information leads to a reduction in the quality of performance of the manufacturing process, even if material and capacity are available [49]. Therefore, nowadays, a core topic regarding the realization of Industry 4.0 is the heterogeneity of the IT landscape, which, for many manufacturing organizations, consist of a variety of software tools to support various processes, and, as a result, data cannot be exchanged without effort [37]. The advances of new IT, such as IoT, cloud computing, and Big Data, enable smart characteristics such as self-sensing, self-organizing, self-adaptive, etc. In the process of implementing smart manufacturing, two prominent trends driven by new IT have emerged. One is that the manufacturing industry is increasingly becoming part of the service industry, i.e., servitization. Another important trend is that the physical world and the cyber world of manufacturing are becoming increasingly integrated [6]. In addition, many smart applications, such as remote monitoring and diagnosis, predictive maintenance, operational analysis, and product usage, are made possible by services [6].

The framework shown in Figure 4 describes the flow in which the different manufacturing process areas are considered in the model. First, the generic process is explained. This consists of five steps: first, it is determined whether there are available monetary means to cover the expenses of the manufacturing operations; second, the preparation and distribution of the planning information needed to specify the required details to plan, monitor, and control the required operations are carried out; third, the required production factors, i.e., material, energy, and human resources are prepared for the process; fourth, the process is performed in which the process stability is key to obtaining the final output product in the fifth step.

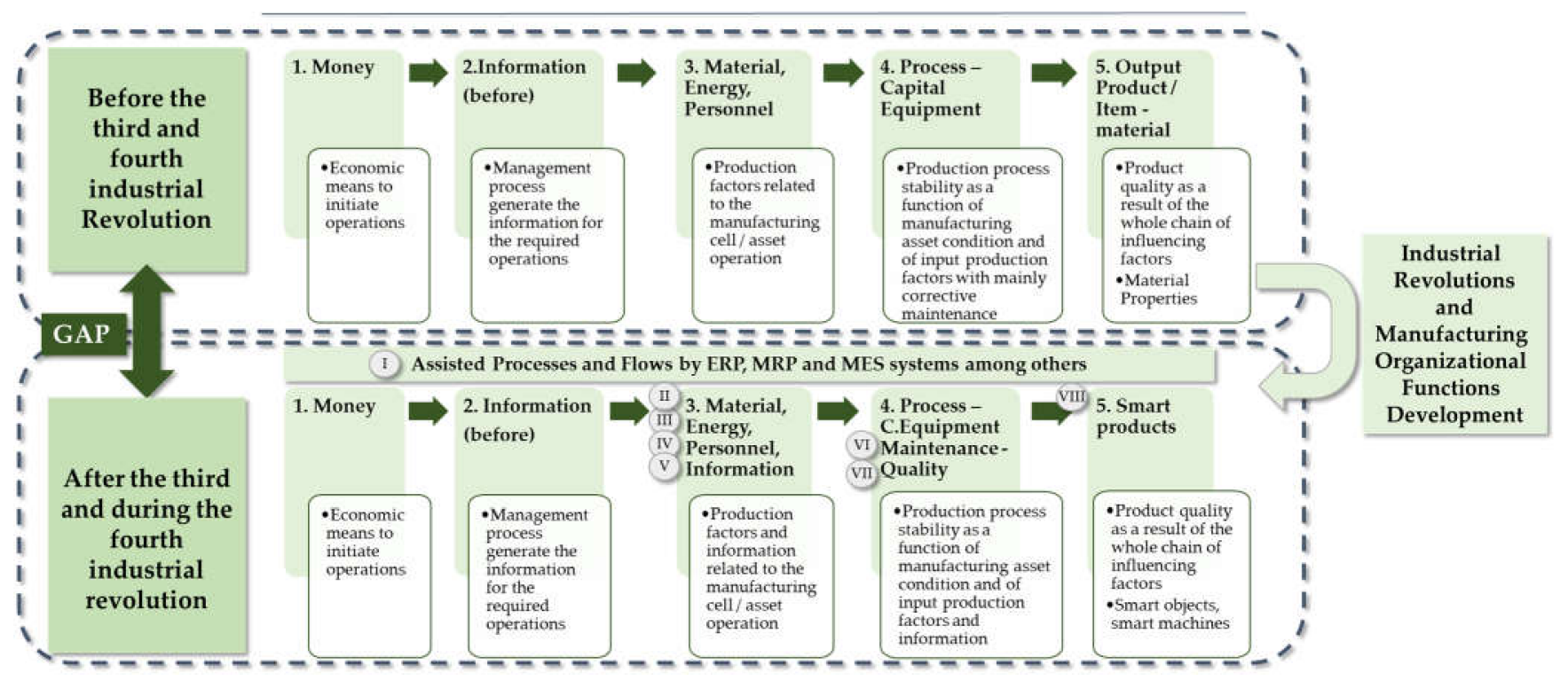

Figure 4. Conceptual framework for functional improvement potentials over the industrial revolutions (the authors' own elaboration).

After describing the five generic steps of the conceptual framework, the differences between the flow for a manufacturing process before the third and fourth industrial revolutions and the flow for current industrial processes can be compared-on the basis of the fact that there are many differences as a result of the industrial revolutions and the 
development of organizational functions. The main differences and potentials are identified in Figure 4. First, the information for managing, planning, monitoring, and controlling the manufacturing process was mainly based on oral and paper form bases, whereas nowadays, manufacturing processes are supported by different systems, such as ERP, MES, SCM, PLM, computer-aided design (CAD), computer-aided manufacturing (CAM), and computeraided technology (CAx) [38]. Secondly, production logistics have evolved since the second industrial revolution. Production systems have been developed with different production strategies and various planning methods for enabling the effective and efficient coordination of material and information flows with suitable management tools independently of the industry. Then, the third area is the evolution of human resource management with leadership and motivation theories versus the classical extrinsic reward-based management. The fourth is energy management that has evolved over time with new technological possibilities as well as with more interconnected and distributed networks. The fifth difference is that the process and all elements can be monitored in real-time due to the emergence of sensors, storage capacity, and velocity in transmitting the manufacturing process data. In this regard, Industry 4.0 opens the path to real-time monitoring and synchronization of real-world activities to the virtual space via the physical-virtual connection and the networking of CPS elements [7]. Therefore, delays can be eliminated or avoided among the process, data analysis, and decisions.

Sixth, the role of maintenance has emerged, mainly from corrective maintenance activities, as a key element in enabling process performance, availability, quality, and stability. The "management approach to achieving the maintenance goals" is referred to as a maintenance strategy [17]. In predictive maintenance, attempts are made to recognize potential or hidden malfunctions through anticipatory measures and to prevent their further development [17]. Today, condition monitoring plays an important role in this context. As soon as there are deviations from normal operating behavior before the malfunction limit is reached, appropriate measures can be initiated. This adapts the maintenance interval to the utilization and saves costs compared to periodic preventive maintenance. The prerequisite for the application of condition-based maintenance is the measurability of condition-determining parameters. This must be technically feasible and economically justifiable [23].

Seventh, the role and importance of quality management and control have significantly increased since the 1930s. The introduction of statistical process control and the application of preventive quality measures in the design processes as well as the development of strategic and company-wide concepts such as TQM have enabled quality management and control strategies, methods, and systems among the key factors for the success of manufacturing organizations.

Finally, the eighth difference is the output product. In the past, it was mainly a physical material with a set of target properties, but nowadays, the product can be a smart product consisting of hardware and software that is capable of containing and transmitting data, and its capabilities can be updated. Smart factories are using embedded CPS for value creation. This enables the smart product to self-organize its required manufacturing processes and its flow throughout the factory in a decentralized manner by interchanging smart data with the CPS [15].

\subsection{Systemic Function-Based Modeling of a Manufacturing Organization}

After having identified the phases of functions development over time in sub-chapter 3.1, and the identification of potentials in different functional areas in sub-chapter 3.2, this sub-chapter converges both approaches into the systemic function-based modeling of a manufacturing organization with the seven considered functions in a model with three planning levels, strategic, tactical, and operational as well as with all the main potential functions that an organizational company can have within the described functional areas. Based on this approach, any organizational structure with its respective employees, systems, methods, and processes can be associated with the functions shown in Figure 5. From this 
figure, it can be observed how there are two axes-the $X$-axis represents the functional areas and their development over time in the same sequence, while the Y-axis consists of the planning levels divided according to functions related to a set of processes-process or task related. Then, based on each combination of planning level (Y-axis) and functional area (X-axis), the different functions are classified, and the organization is built and continuously developed as new functions emerge and existing functions evolve. This approach enables possessing all the potential functions of any organization; therefore, an assessment of a manufacturing firm can be performed by investigating if the function exists, how it is performed, and its effectiveness and efficiency in any given manufacturing organization:
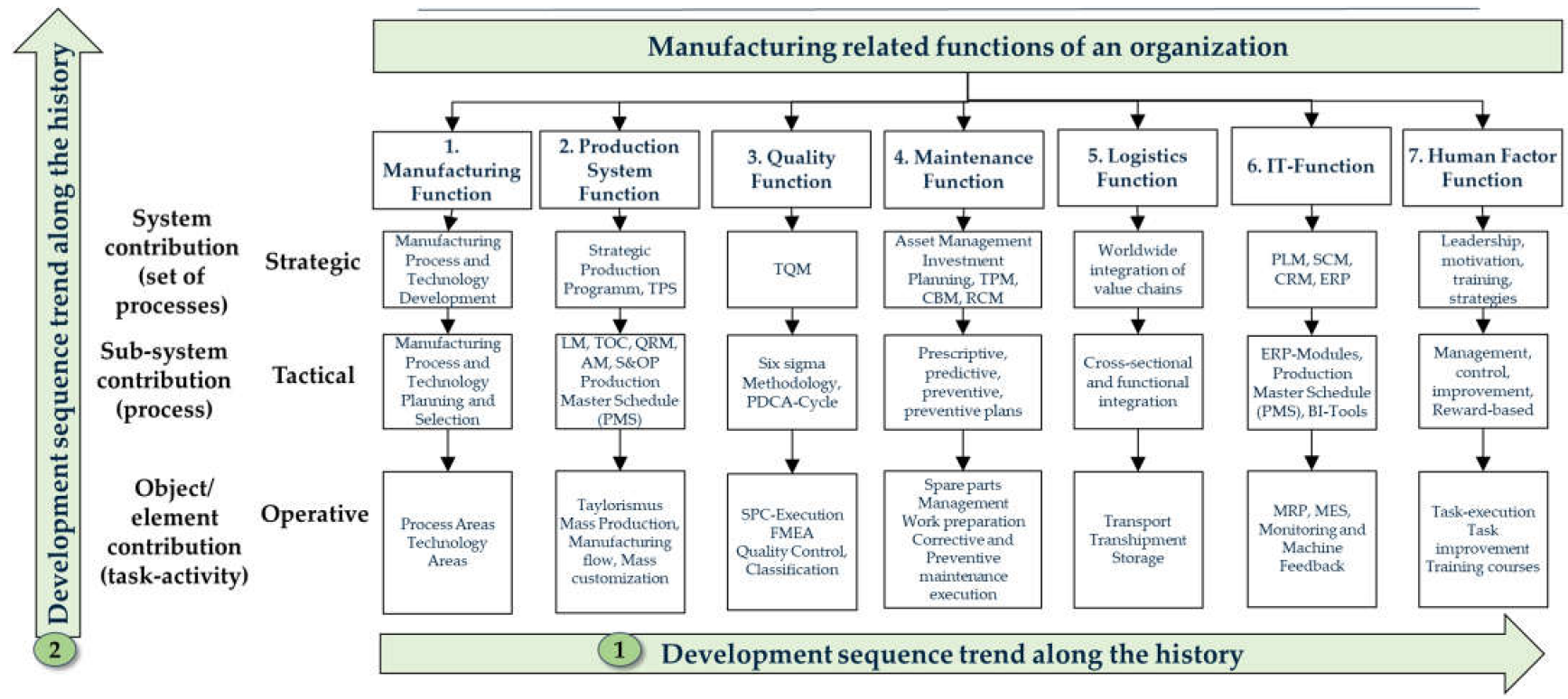

Figure 5. Manufacturing Functions Development within an Organization (own elaboration).

\subsection{FMEA Model for Developing Improvement Plans in Manufacturing Organizations}

This sub-chapter serves to generate a model of how to make a holistic diagnosis of malfunctions within manufacturing organizations by analyzing the functions performed by the firm. For any given organization, the deviations in key performance indicators (KPIs) are a matter of daily activity tracking, reporting, and processing. Therefore, organizations begin the search for the cause of the perceived effect, that is, the deviation. In this process, on many occasions, the result is not satisfactory, without a true outcome of the final cause. For that purpose, Figure 6 assumes that any given deviation needs to assess all functional areas, their performances, and interrelationships in order to identify the cause of an organizational indicator deviation or any other malfunction.

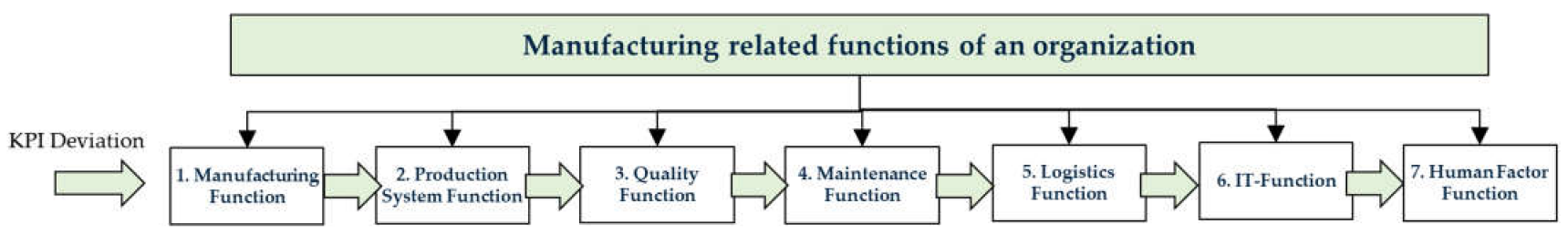

Figure 6. FMEA Process for Function limitation or bottleneck: diagnosis sequence at the organizational functional areas level (the authors' own elaboration).

Based on the model, a common process could be as follows:

1. KPI deviation is identified. 
2. KPI attracts the attention of top management.

3. A process for searching the cause is initiated:

a. If the deviation identified refers to a cross-functional manufacturing indicator, normally this process starts from the operative manufacturing function and goes through the organization;

b. If the deviation refers to a specific functional area such as the quality rate, the analysis starts from the related functional area, quality function, in relation to the manufacturing function.

4. The sequence is normally the same as the historic evolution of the different functions.

5. The cause-effect analysis of malfunctions of organizational functions is normally not analyzed with a global holistic perspective considering all the functional areas and interrelationships. However, it is normally assessed in the manufacturing and technical areas such as quality and maintenance, and on occasions, moves up to other logistics and IT functions. In the process of many malfunctions, a real cause is not identified, and occurs as "sporadic cases"; therefore, on many occasions' managers do not know why certain projects fail to make it impossible to learn from experience.

6. For doing so, first, it is necessary to analyze the maturity model of the organization by functional area to determine in which evolution state the organization is at. The following steps are considered:

a. Current state knowledge: Know the function maturity level of each functional area in the different planning levels according to the historic evolution. A company state will be determined by the moment it was created, the functions implemented at this time, the improvement projects performed until now, and the success, partial success, or failure of this project.

b. Identify the problem.

c. Perform an holistic malfunction analysis based on an organizational function FMEA process with the help of mapping the interrelationships among functions.

d. Optimize the process for executing the function that needs improvement.

e. Determine the measures for the technical, organizational, or human factors for executing the new process.

f. Implement the plan.

These later steps for developing measures for function development are specified in Figure 7, also considering the alignment with the organizational goals: 


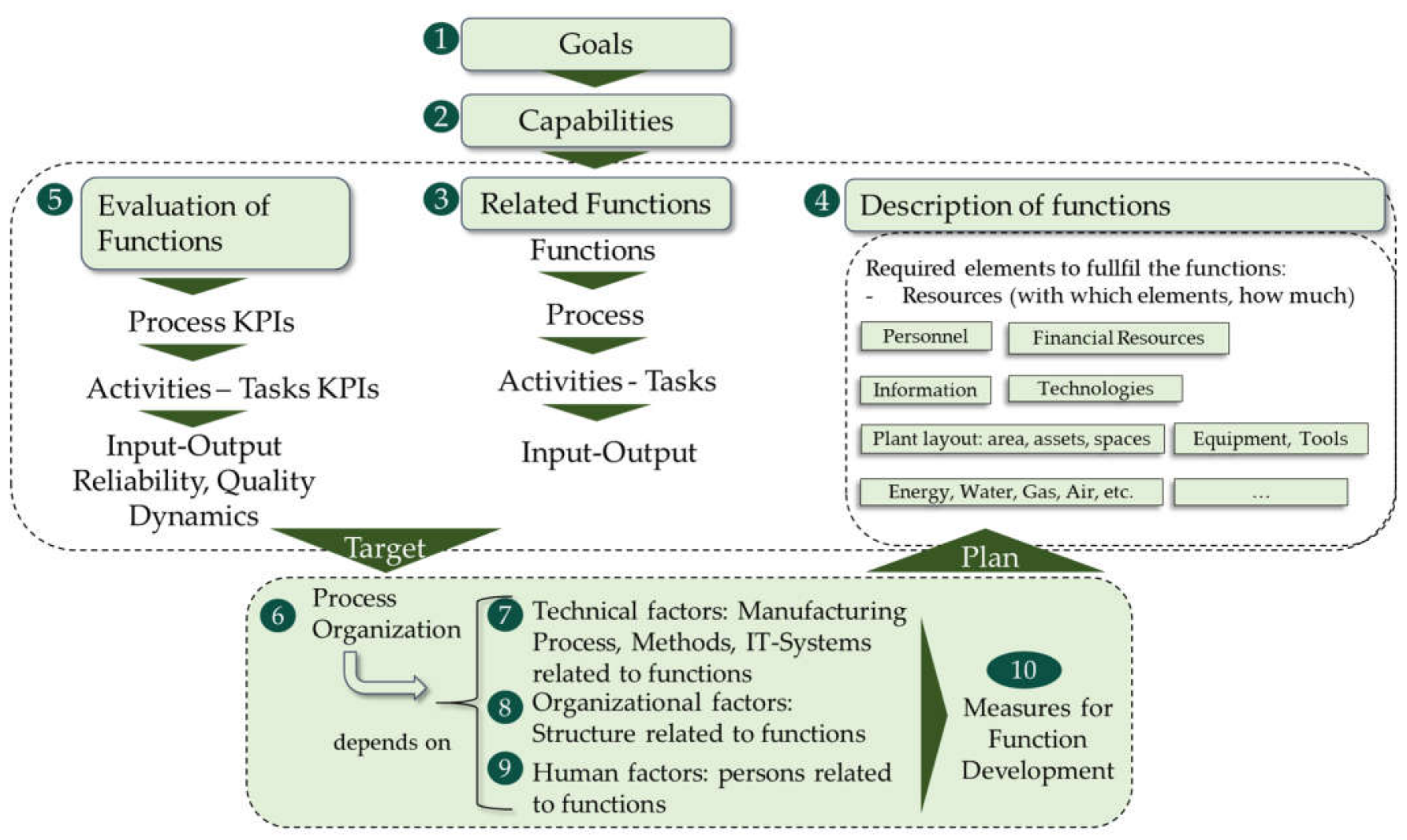

Figure 7. Development of Functions aligned with organizational goals (the authors' own elaboration).

\section{Simulation Case Study}

First, the purpose of the simulation case study and its scope were defined. The goal of the simulation case study was to develop an optimization process that simulates the improvement of the functions within a manufacturing organization. The functions follow the sequence of the historical development of functions shown in Chapter 3. Moreover, after finishing the normal development of the functions, a second variant of the case study is developed. This variant simulates three different cases in which the qualification levels or the goals alignment of managers within the organization differ from the equilibrium that provides better results. In both cases, the scope of the study was to create:

- A generic simulation model consisting of the most relevant manufacturing functions that would serve as a basis for developing specific evaluations for any kind of industrial organization.

- Specific simulation models for each main function in the optimization process that repeats the translation of the evolution of functions. The scope of these models did not include all associated functions, resources, and data.

- A holistic exemplary digital model that could serve as the basis for developing functions within organizations as well as for monitoring their performance and based on this assessment being able to make a diagnosis of malfunctions and their origin within the process and organizational structure of industrial firms.

The hypothesis of the case study was:

- The improvement of all relevant indicators along the historical evolution of functions within industrial organizations.

- The importance of each function as each could become a limiting factor acting as a bottleneck.

- The significant implications on key indicators of the qualification factor as well as of the alignment of employees to organizational, department, and position goals. 
For the methodological framework, the following steps were followed:

1. Definition of the objective, scope, and hypothesis.

2. Manufacturing organizational functions definition.

3. Determination of KPIs.

4. Development of assumptions and simulation logic.

5. Generation of the simulation models and definition of scenarios.

6. Validation of simulation models.

7. Simulation and extraction of results.

8. Interpretation of results.

\subsection{Design of the Generic Model of Functions for Industrial Organizations}

First, the description of the general structure of the simulation models is performed. This structure was applied to all simulation model variants within the simulation case study. The structure was developed to provide the necessary and sufficient detail level and mix consisting of the manufacturing organizational functions with their associated organizational structure, employees, and organizational processes within a production system within a supply chain with suppliers and distributors in order to answer the research question. Thus, as can be seen in Figure 8, the structure considered was developed to serve as a generic framework applicable for any sector. Moreover, the production system consisted of technical processes including the transportation, warehousing, and production of finished products as well as management processes, systems, and organizational structure from operational to strategic levels.

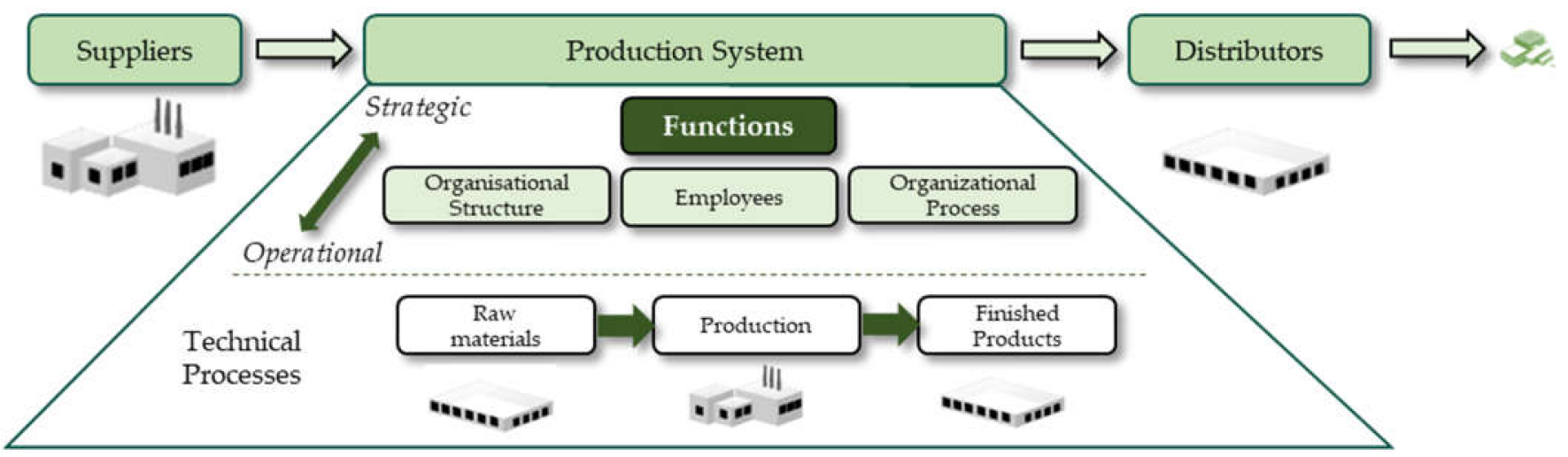

Flow $\quad$ III $\quad$ Production plant, line, machine group

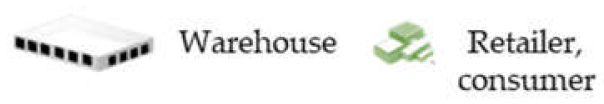

Figure 8. Structure of the simulation case study (the authors' own elaboration).

The functions implemented in the simulation model refer to an organizational structure consisting of a CEO (chief executive officer) and seven functional areas. The areas are the manufacturing process, production system, quality, maintenance, logistics, human resources, and IT functional areas. All areas have three horizon levels with their different functions and employees of the organization associated with those functions as well as to the processes that are performed for the implementation of the functions they are responsible for. Moreover, while all simulation models maintained this structure over the simulation period, capacities, methods, systems, human resource structures, and technologies changed depending on the simulation model influencing the model behavior. 


\subsection{Key Performance Indicators}

The research goal was to study the behavior of the different models in different demand scenarios and configurations of a production system. The results were calculated for all model simulations to evaluate the response according to the following key performance indicators:

- Cumulated market demand (\# thousand products);

- Cumulated real demand (\# thousand products);

- Cumulated production (\# thousand products): the cumulative sum of all units produced over the 500 simulated-production weeks;

- $\varnothing$ Utilization rate of the production plant (\%);

- $\varnothing$ Availability of the production plant (\%);

- $\quad \varnothing$ Performance at the final production step (\# thousand products/week);

- $\varnothing$ Quality at the final production step with one-way and no loops (\%);

- $\varnothing$ Labor productivity (products/employee $\times$ week);

- Cumulated stocks (\# million products);

- $\quad \varnothing$ Production lead time (\# weeks);

- Cumulated service level (\%);

- Cumulated sales (USD million);

- Cumulated operational costs (USD million);

\subsection{Assumptions}

Assumptions were defined to simplify the model with a focus on the simulation goal:

- Time restrictions: 10 working years in periods of weeks assuming 50 working weeks per year, 500 periods in order to evaluate implications in the manufacturing organization in the short, medium, and long terms.

- Fixed lead times for production processes, material transport, and employee movements.

- Real demand that is requested by the manufacturing organization depends on the service level. As a result, the company cannot cover the whole potential market demand if the service level is not appropriate.

- Each order had a production unit.

- Same demand using replication for all the models.

- Same initial situation, with initial inventory in the different warehouses for all the models.

- Same number of employees with the same initial distribution for all the models.

- Same supply chain distribution network (production facility, warehouses, etc.).

- The warehouses had no stock capacity limitations.

- There were no transport limitations between the different production stages.

- One product unit was assumed to be in a mature stage with stable demand and provided a sales value of USD 10,000/unit. The second product was in the process of being launched and provided USD 20,000/unit. These values were used to calculate sales. It was assumed that the new model would have a loss in volume due to unknown future demand.

- The simulation model considered sales loss starting from a customer order lead time greater than 60 days.

- A product was considered a finished product after it left the production facility.

- If no human factor malfunctions, it is assumed that the employees have adequate qualification as well as alignment with organizational, department, and position goals they are in charge of.

\subsection{Simulation Models and Scenarios}

Simulation models were developed based on the conceptual model, i.e., based on the different historical states of manufacturing organizations based on their functions evolution. For this study, the following simulation models (SMs) were defined as:

9. Base model (BM); 
10. Production technology (PT);

11. Operative production management (OPM);

12. Control and prevention of technical limitations (TL);

13. Global logistics and systems expansion towards TQM (LSQ);

14. Industry 4.0 (I4.0);

15. Human factor malfunction in the strategic, tactical, operative levels (HF3);

16. Human factor malfunction in the tactical, operative levels (HF2);

17. Human factor malfunction in the operative level (HF1).

The simulation models were presented as small incremental cases studies along the historical process of organizational functions evolution in the different functional areas of an organization. This meant that the PT effects were added to the OPM effects, and, consequently, the TL and LSQ effects were added to the I4.0 implications. Moreover, the simulation case study begins with an initial situation, BM, in which an organization presents capacity, technical bottlenecks, a push production strategy, neither quality nor maintenance management, as well as a lack of information and logistics management other than information delays and the classical operative logistics functions of TTS logistics. Based on these arguments, the following Table 1 presents the logic of the simulation models.

Based on the logic described, the simulation models were developed. The main inputs for the model were the market demand for the products considered, and the capacities for suppliers, production processes, and distribution as well as the specific settings for the different models depending on the measures previously described. The output values were the key indicators that were used to evaluate the results.

There was one simulation scenario that was read from an Excel sheet as the input demand for all the simulation models. In the demand scenario simulated, it is composed of one product with a stationary demand pattern and one product initiating with a trend demand pattern during its launch process and then followed by a stationarity demand pattern. Therefore, the demand pattern simulated tried to simulate a manufacturing organization with an existing production level in a mature stage while trying to introduce a new product to the market. The demand read by Vensim software is shown in Figure 9.

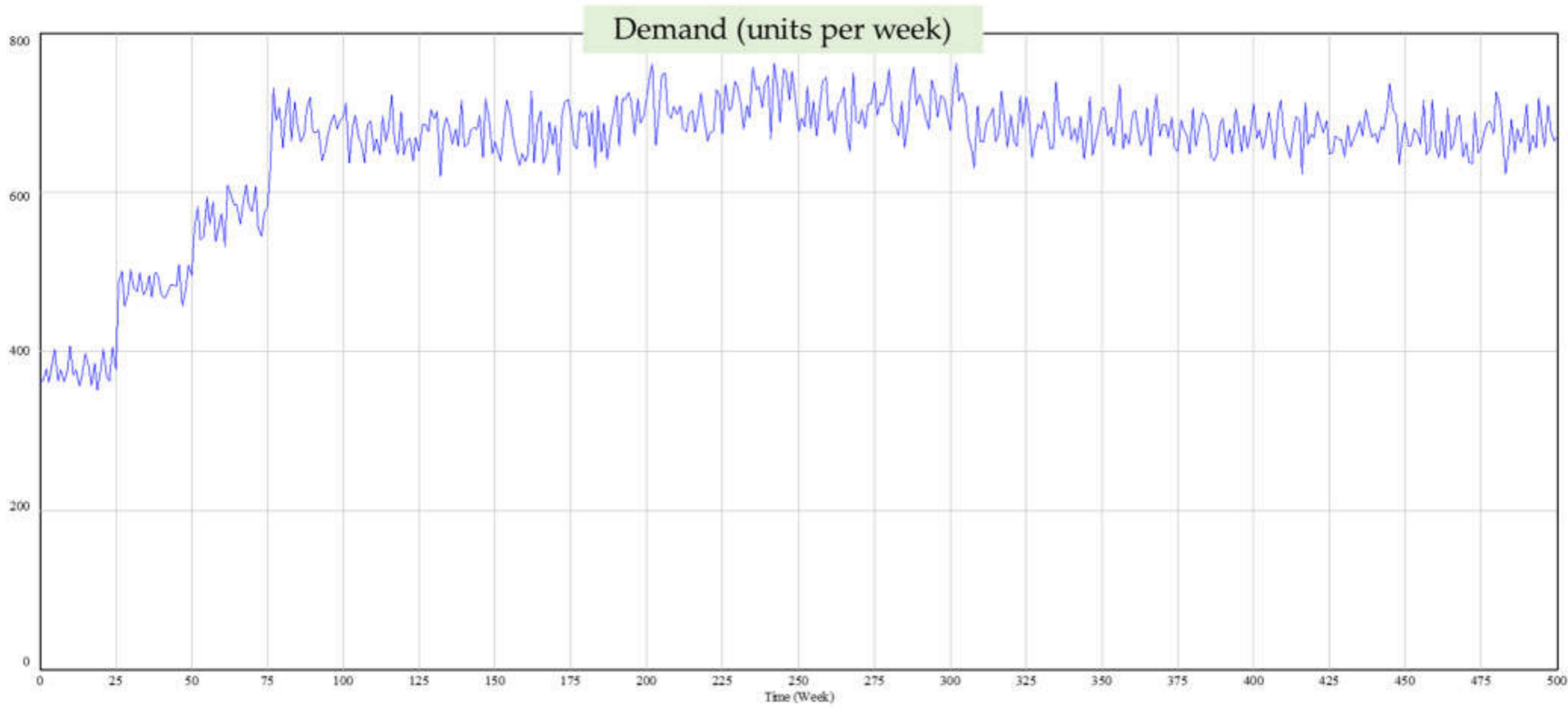

Figure 9. Demand level scenario for all simulation models (the authors' own elaboration). 
Table 1. Simulation models: logic formulation.

\begin{tabular}{|c|c|c|c|c|}
\hline \multirow{2}{*}{ No. } & \multirow{2}{*}{ Simulation Models } & \multicolumn{3}{|c|}{ Logic Formulation } \\
\hline & & Measures & Description of Impacts & Impact on KPIs \\
\hline 1 & Base Model & No measures & Initial Situation & Base KPIs \\
\hline 2 & Production Technology & $\begin{array}{c}\text { Investment in new } \\
\text { equipment for capacity } \\
\text { expansion }\end{array}$ & $\begin{array}{l}\text { Increase in painting } \\
\text { production capacity }\end{array}$ & Higher Production Volume \\
\hline 3 & $\begin{array}{c}\text { Operative Production } \\
\text { Management }\end{array}$ & $\begin{array}{c}\text { Scientific Management, } \\
\text { Taylorism }\end{array}$ & $\begin{array}{c}\text { Work organization and } \\
\text { management }\end{array}$ & Higher Performance Rate \\
\hline 4 & $\begin{array}{l}\text { Control and Prevention of } \\
\text { Technical Limitations }\end{array}$ & $\begin{array}{l}\text { SPC, Preventive } \\
\text { Maintenance }\end{array}$ & $\begin{array}{l}\text { Improve condition of } \\
\text { equipment, better control } \\
\text { of product and process } \\
\text { quality by statistical means }\end{array}$ & $\begin{array}{l}\text { Higher Quality Rate, } \\
\text { Higher Availability Rate }\end{array}$ \\
\hline 5 & $\begin{array}{c}\text { Global logistics and } \\
\text { systems expansion towards } \\
\text { TQM }\end{array}$ & $\begin{array}{c}\text { Pull Strategy, IT-Systems, } \\
\text { TQM, Predictive } \\
\text { Management, TPM }\end{array}$ & $\begin{array}{l}\text { Higher Planning Accuracy, } \\
\text { Lower information delays, } \\
\text { Improve Quality and } \\
\text { Maintenance Strategic } \\
\text { Planning }\end{array}$ & $\begin{array}{c}\text { Lower Stocks, } \\
\text { Higher Service Levels, } \\
\text { Shorter Customer Order } \\
\text { Lead Times, } \\
\text { Higher quality rate, } \\
\text { Higher availability rate }\end{array}$ \\
\hline 6 & Industry 4.0 & $\begin{array}{l}\text { New I4.0 Technologies } \\
\text { implementation }\end{array}$ & $\begin{array}{c}\text { Real-time information, } \\
\text { Horizontal and vertical } \\
\text { integration, Prediction } \\
\text { capabilities, } \\
\text { Assisted Systems }\end{array}$ & $\begin{array}{c}\text { Higher Performance Rate, } \\
\text { Higher Quality Rate, } \\
\text { Higher Availability Rate, } \\
\text { Shorter Customer Order } \\
\text { Lead Times } \\
\text { Higher Service Levels }\end{array}$ \\
\hline 7 & $\begin{array}{l}\text { Human factor malfunction } \\
\text { in the strategic, tactical, } \\
\text { operative levels }\end{array}$ & $\begin{array}{l}\text { Lack of qualification of } \\
\text { CEO, no correct alignment } \\
\text { of goals of Quality Director } \\
\text { and Assembly Manager } \\
\text { and Employees }\end{array}$ & $\begin{array}{l}\text { Lower decision-making } \\
\text { capabilities. Sub-optimal } \\
\text { decisions, without the } \\
\text { correct timing }\end{array}$ & $\begin{array}{l}\text { Lower overall performance } \\
\text { of company KPIs in all } \\
\text { functional areas }\end{array}$ \\
\hline 8 & $\begin{array}{l}\text { Human factor malfunction } \\
\text { in the tactical, operative } \\
\text { levels }\end{array}$ & $\begin{array}{c}\text { Misalignment of goals of } \\
\text { Quality Director and } \\
\text { Assembly Manager and } \\
\text { Employees }\end{array}$ & $\begin{array}{c}\text { Decision-making } \\
\text { capabilities oriented to } \\
\text { other goals }\end{array}$ & $\begin{array}{c}\text { Lower performance of } \\
\text { company KPIs in quality } \\
\text { and manufacturing areas } \\
\text { and implications in related } \\
\text { functional areas }\end{array}$ \\
\hline 9 & $\begin{array}{l}\text { Human factor malfunction } \\
\text { in the operative level }\end{array}$ & $\begin{array}{c}\text { Misalignment of goals of } \\
\text { Assembly Manager and } \\
\text { Employees }\end{array}$ & $\begin{array}{c}\text { Decision-making } \\
\text { capabilities oriented to } \\
\text { other goals }\end{array}$ & $\begin{array}{l}\text { Lower performance of the } \\
\text { assembly manufacturing } \\
\text { functional sub-area and } \\
\text { implications in related } \\
\text { functional areas }\end{array}$ \\
\hline
\end{tabular}

\section{Simulation Results}

The simulation results for the cumulative functional developments as well as for the three models with different levels of human factor malfunctions are shown in Tables 2 and 3. All simulation models are compared for the same input demand. However, not all simulation models had the same real demand (i.e., the effective demand that the company was asked for by its customers). The reduction resulted from the consequences of poor service levels and long customer-order lead times. As it can be seen, total production levels over the simulation increased from the BM up to the I4.0 model, with the higher increase in production - almost 90,000 units as well as in profits from the TL to the LSQ model. In addition, availability, performance, and quality rates improved in the simulation models from the BM to the I4.0 model. In addition, the stock levels reduced significantly up to and including the LSQ model. The production order lead times decreased from 192 days to 47 days when functional improvements were applied. Finally, sales multiplied by more 
than a factor eight from the BM to the I4.0 model, and operational costs were at the same level in the BM and I4.0 models while the production volume was almost six times higher.

Table 2. Simulation results for the simulation models with cumulative functional developments.

\begin{tabular}{|c|c|c|c|c|c|c|c|}
\hline \multirow{2}{*}{ No. } & \multirow{2}{*}{ Key Indicator } & \multicolumn{6}{|c|}{ Simulation Models: Cumulative Developments } \\
\hline & & 1-BM & 2-PT & 3-OPM & $4-\mathrm{TL}$ & 5-LSQ & 6-I4.0 \\
\hline 1 & Market demand ( $10^{3}$ products $)$ & 326.7 & 326.7 & 326.7 & 326.7 & 326.7 & 326.7 \\
\hline 2 & Real demand ( $10^{3}$ products) & 59.3 & 72.5 & 142.4 & 176.7 & 267.9 & 317.9 \\
\hline 3 & Production (10 3 products) & 55.7 & 64.5 & 121.7 & 150.7 & 235.3 & 291.9 \\
\hline 4 & Utilization rate $(\%)$ & 13.8 & 16.0 & 30.4 & 37.6 & 58.8 & 73.0 \\
\hline 5 & Availability rate (\%) & 51.6 & 51.6 & 51.6 & 63.2 & 88.9 & 95.0 \\
\hline 6 & Performance rate $(\%)$ & 44.3 & 44.1 & 79.6 & 78.3 & 83.4 & 99.6 \\
\hline 7 & Quality rate (\%) & 87.5 & 87.1 & 84.3 & 87.0 & 92.4 & 93.0 \\
\hline 8 & Stocks ( $10^{6}$ products) & 3.5 & 4.7 & 10.6 & 12.0 & 1.5 & 1.9 \\
\hline 9 & $\begin{array}{l}\text { Labor productivity } \\
\text { (products/empl. } \times \text { year) }\end{array}$ & 11.1 & 12.9 & 24.3 & 30.2 & 47.1 & 58.4 \\
\hline 10 & Production lead time (days) & 192 & 182 & 124 & 102 & 67 & 47 \\
\hline 11 & Cumulated service level (\%) & 48.6 & 61.0 & 82.4 & 88.4 & 90.2 & 96.6 \\
\hline 12 & Sales (million USD) & 600 & 731 & 1630 & 2171 & 3890 & 4865 \\
\hline 13 & Operational costs (million USD) & 546 & 614 & 931 & 1017 & 517 & 561 \\
\hline
\end{tabular}

Table 3. Simulation results for the high demand level scenario.

\begin{tabular}{|c|c|c|c|c|c|}
\hline \multirow{2}{*}{ No. } & \multirow{2}{*}{ Key Indicator } & \multicolumn{4}{|c|}{ Simulation Models: Human Factor Malfunctions Versus 6-I4.0 } \\
\hline & & 7-HF3 & 8-HF2 & 9-HF1 & 6-I4.0 \\
\hline 1 & Market demand ( $10^{3}$ products) & 326,738 & 326,738 & 326,738 & 326,738 \\
\hline 2 & Real demand $\left(10^{3}\right.$ products $)$ & 82,699 & 243,634 & 276,302 & 317,942 \\
\hline 3 & Production $\left(10^{3}\right.$ products $)$ & 72,282 & 208,998 & 243,818 & 291,922 \\
\hline 4 & Utilization rate $(\%)$ & 18.0 & 52.3 & 61.0 & 73.0 \\
\hline 5 & Availability rate $(\%)$ & 93.0 & 95.0 & 95.0 & 95.0 \\
\hline 6 & Performance rate $(\%)$ & 101.8 & 100.2 & 100.0 & 99.6 \\
\hline 7 & Quality rate (\%) & 84.8 & 88.7 & 92.3 & 93.0 \\
\hline 8 & Stocks $\left(10^{6}\right.$ products $)$ & 5.2 & 10.8 & 13.4 & 1.9 \\
\hline 9 & $\begin{array}{c}\text { Labor productivity } \\
\text { (products/empl. } \times \text { year) }\end{array}$ & 14.5 & 41.8 & 48.8 & 58.4 \\
\hline 10 & Production lead time (days) & 183 & 78 & 64 & 47 \\
\hline 11 & Cumulated service level (\%) & 67.2 & 93.2 & 97.6 & 96.6 \\
\hline 12 & Sales (million USD) & 829 & 3379 & 4043 & 4865 \\
\hline 13 & Operational costs (million USD) & 642 & 975 & 1126 & 561 \\
\hline
\end{tabular}

As shown in Table 3, the HF3 model presents almost the same level of results as the $\mathrm{BM}$ and PT simulation models, meaning that if a manufacturing organization has three key managers as well as some operative employees with a lack of qualification as well as with goals only partially aligned to those of the organization, the performance and, therefore, the viability of the company is strongly damaged. As a result, a company can have the appropriate technologies, quality, maintenance, production, logistics, and IT 
systems, but none of them will be valid for the overall system performance if the other functional factors, such as the human factor, are not balanced and aligned. Otherwise, the manufacturing organization will converge to an equilibrium that is far from the optimum rendering the improvements and developments in other functions non-useful. Thus, if new equipment, new methods, new systems are underutilized, this means that investments are not providing the benefits expected and consequently the long-term sustainability of the company is compromised. In the same direction, but with a lower level of severity, models HF2 and HF1 show significant lower overall performance in comparison with the I4.0 model in which it is assumed that the human factor functions are fully aligned with technologies, methods, systems, and goals based on appropriate qualifications, which a difficult task in practice considering the dynamics of a firm. Only one indicator is better for the HF1 than for the I4.0 model, which is the service level, by one percent; however, it is better for almost 50,000 lower production units and can also happen that, due to the assembly manager goals, production is storage in the process incrementing the stock levels, as they are ten times higher than in the I4.0, enabling secure service levels from stocks. Finally, the results of Table 3 show clearly how all the improvements in manufacturing functions reduce their effectiveness or are non-existent if not all functional areas are considered-in the latter case, the human factor function. Specifically, for Industry 4.0, currently in progress, it cannot reach its potential without correctly integrating the human factor with the new technologies for successful interaction and thus avoiding the cases shown in the results of Table 3.

\section{Discussion}

Today, many manufacturing organizations have difficulties identifying where the lack of organizational performance comes from. Success and failure cases are often analyzed and discussed, however, for many of them, the real cause leading to the observed effect is overseen. Moreover, this occurs at all levels, from strategic to operational levels, and managers are confronted with a complex set of systems, processes, and organizational structures with different interests in which they must manage to fulfill their function.

In this context, managers can use a potential instrument that is neither known nor applied for most managers across all management levels. This instrument is based on the conceptual model developed, which is also based on the historical development of functions within manufacturing organizations along the industrial revolutions. By applying it to an organization, a manager or employee can identify which functions the company, department, or activity founded and how they develop over time, i.e., which other functions were implemented, how, and with which level of success. By doing so, a manager or an employee can learn from the history of the company, then use this knowledge for managing and controlling their functions, since the individual will know which functions are fully implemented and working properly and which functions are an improvement potential. Then, the individual is prepared for the function since the employee will be aware of all the things that influence the function other than the function itself, i.e., the individual will have a clear picture of the current state of the function and the associated interrelated factors. Moreover, the individual can support the design and implementation of future development activities for the functions under their responsibility. For performing all those activities, a digital twin model representing their functions will enable to speed up the learning process, the simulation of what-if scenarios, the identification of improvement potentials, as well as the implementation of these improvements.

In this context, any manager or individual within an organization must identify the technical, organizational, or human factors that are limiting the performance for an optimized realization of the function under their responsibility. These limiting factors on the operative level, are, for instance, the efficiency or performance of a production line or the machine availability; on the tactical level, they can be the correct implementation of production planning and preventive maintenance plans, and on the strategic level, they are the alignment of functions to the organizational targets and the correct assignment of functions to individuals considering both the evolution of the function and of the individual. 
In addition, most organizations have areas or departments acting as separate "kingdoms" as organizational silos with functions distributed and fragmented with divergent goals. As a result, there are normally inefficiencies; that is, it is not known who is responsible for the disruption, what its cause is, and how it should be analyzed. For clearing this situation, an analogy to the FMEA needs to be performed for all functions of the organization for obtaining a timely and correct diagnosis enabling the improvement of the organization. Here, it is where a digital twin model fed by real data and performing simulations can provide significant benefits for the organization, its managers, and employees at all levels.

As it has been shown in the previous chapters, one organization can be at different development levels for different functions, i.e., might be an organization with a quality function developed up to the existing possibilities of the 2000s while the human factor is still considered only reward based, such as in the 1930s. Therefore, and as has been proven by the simulation results, the developments of the different functions of an organization need to be balanced in order to reach the optimum operating behavior of the firm. In any other case, if one of the functions is managed or developed with lower functionalities, this function will limit the overall performance of the firm.

Finally, after having shown the evolution of the different functions of a manufacturing organization along the industrial revolutions, it becomes clear that together with the fourth industrial revolution, the advent of the fifth industrial revolution is about to arrive focusing on the revolution of the human factor. This refers to the question of how to integrate the human factor as a final decision-maker within the Industry 4.0 environment. For that purpose, human-machine interfaces need to be explored and are required to exploit the full potential of the fourth industrial revolution, as shown in this paper. Furthermore, if the human factor is not aligned with the capabilities of the other elements of the manufacturing organization, the optimum is not achieved and the global performance decreases dramatically. The human factor revolution is becoming a necessity for the full deployment and utilization of technologies of the fourth industrial revolution, as shown in Figure 10.

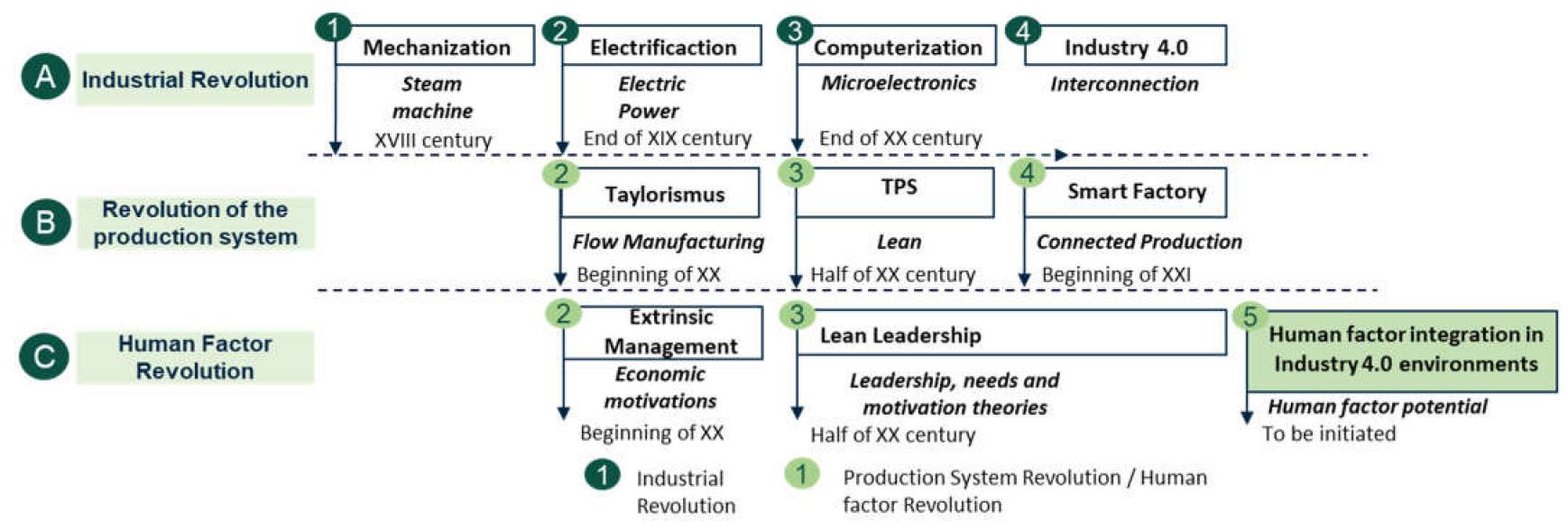

Figure 10. Human factor integration in I4.0 environments: a revolution (the authors' own elaboration).

\section{Conclusions}

This section is divided into theoretical, managerial, and empirical conclusions, in addition to an explanation of the limitations of the research performed and a description of the potential future research derived from the findings.

Theoretical conclusions: This study identifies manufacturing challenges such as the difficulties of organizations to identify the logic behind non-successful organizational performance. For that purpose, the paper tackles this by developing a holistic approach for modeling manufacturing organizations based on their functions. In order to achieve these goals, the conceptual model also provides a classification of functions based on their evolution along the industrial revolution. From this analysis, it can be seen how manufacturing was the first area to initiate the development of industrial capabilities starting from the substitution of human and animal 
force by machines and developing continuously until now. Secondly, it was shown that the revolution of the productive systems followed with Taylorismus in the second industrial revolution and has, until now, developed methodologies such as lean manufacturing and Industry 4.0. Third, between the second and the third industrial revolution, it has been shown how the developments in quality and maintenance management started. As a fourth step, once the process is performed based on good planning, quality, and stability maintained over time, it was time for opening the development of global value chains. For that purpose, two new areas of development were initiated in the third industrial revolution, i.e., information systems and logistics. By doing so, globalized supply chains with ubiquitous management and control of operations were possible. Finally, the capabilities to gather and analyze large amounts of data are for the very first time possible due to the technological development of the fourth industrial revolution that makes it possible to collect and process data in real time and convert it into virtual enabling decision-making based on updated information and analysis. Moreover, virtual models enable the ability to reproduce past scenarios and simulate future ones in order to predict the behavior of the system to obtain valid conclusions for any process providing lessons learned and insights about the measures that need to be performed to prevent the occurrence of failures as well as to avoid corrective measures.

Managerial conclusions: The paper provides a description of the main issues in manufacturing organizations that can limit performance and viability over time. From this perspective, the paper is a guideline of what can go wrong, and, therefore, helps managers to identify the final cause leading to inefficient performance. Moreover, the paper provides a perfect framework to reflect and analyze the functions and capabilities that the company has while considering the company's foundation time and the historical development of the company. By doing this, managers can obtain a global picture of why some functions provide expected functionalities and why other functions do not provide them as for instance, in a business transformation process resistance at the department level to not lose "their part of the cake", i.e., their "power of influence on the function" and as a result, the new function was created with problems, lack of support, and / or team spirit. In this context, the relevant changes related to the manufacturing organization through the industrial revolutions were identified as an opportunity to develop improvement strategies and the conceptual model applied to digital twin models can be a key tool in managerial decision making.

Empirical conclusions: To prove the utility of this new concept, a simulation example for a manufacturing organization was created by applying system dynamics. Nine different models were successfully developed. The models represent an analogy of the evolution of functions along the industrial revolution and help to assess the organizational performance as well as to identify weak points thanks to the detection of inefficiencies. The benefits along the models provide global optimization of the production system grounded in higher manufacturing process performance, better distribution and planning of tasks at the operative level, improved quality control leading to better product quality, and maintenance management providing higher manufacturing system availability, followed by improved IT systems, logistics, quality management, and Industry 4.0 technologies.

The results show how several factors can limit the potential of the functions, and as a result, the capabilities of an organization lead to a decreased probability of remaining viable over time. Among the relevant factors, there are technical, organizational structure and processes, as well as human-related factors. In conclusion, the conceptual approach and the applied simulation case study provide managers with a decision-making model for successful management and control of operations while also ensuring well-directed continuous optimization based on a successful diagnosis of improvement potentials in any function of the organization.

Limitations of the research work:

- The conceptual framework of the assessment methodology was not developed in the operative level and for specific cases. 
- Individual interactions among staff, machines, robots, and other elements were not considered in the simulation model.

- The full complexity of manufacturing processes was not built in detail.

- The organization structure and interfaces were not considered in the simulation model.

- Certain quality requirements of the product were not considered.

- Investment and costs were assumed.

- The concept was not proved in any company.

Future research based on this study's findings could focus on the following:

- Transferring this research method to real manufacturing organization and applying it as a digital twin tool or an assistance tool for strategic, CEOs and vice presidents, for tactical level, sales, production, quality and maintenance leaders, and operative levels, by centralizing all data related to the manufacturing organization, functional area, or function, thereby allowing better planning based on updated information of all interrelated factors as well as providing a tool for the assessment and the simulation of what-if-scenarios in real time.

- Considering organization units, persons, relationships, and their communication within the simulation model.

- Improving the model based on implementation feedbacks as well as applying it to production networks with several production plants.

- Improving the simulation model with better connection to the physical world as well as with expanded data analytics and artificial intelligence to provide suggestions in order to assist human decision-making activities.

In summary, this study highlights the potential benefits of the conceptual approach and the applied simulation case study, allowing better decision making for top managers, department leaders, and operative management levels. This ensures continuous optimization along the organizational functional structure. The proposed model offers an example of how manufacturing organizations can be assessed, managed, and controlled in an integral way. As a result, the proposed methodology represents a useful tool for organizations and managers in order to increase their efficiency, competitiveness, and therefore, viability over time.

Author Contributions: Conceptualization, S.G.-G. and M.G.-G.; methodology, M.W. and S.G.-G.; software and programming, S.G.-G.; Validation, M.W. and S.G.-G.; data analysis, S.G.-G.; writing (review and editing), S.G.-G. All authors have read and agreed to the published version of the manuscript.

Funding: This research received no external funding.

Institutional Review Board Statement: Not applicable.

Informed Consent Statement: Not applicable.

Conflicts of Interest: The authors declare no conflict of interest.

\section{References}

1. Wang, S.; Wan, J.; Li, D.; Zhang, C. Implementing smart factory of industrie 4.0: An outlook. Int. J. Distrib. Sens. Netw. 2016, 12, 3159805. [CrossRef]

2. Vaidya, S.; Ambad, P.; Bhosle, S. Industry 4.0-A glimpse. Procedia Manuf. 2018, 20, 233-238. [CrossRef]

3. Permin, E.; Bertelsmeier, F.; Blum, M.; Bützler, J.; Haag, S.; Kuz, S.; Özdemir, D.; Stemmler, S.; Thombansen, U.; Schmitt, R.; et al. Self-optimizing production systems. Procedia Cirp 2016, 41, 417-422. [CrossRef]

4. Chen, B.; Wan, J.; Shu, L.; Li, P.; Mukherjee, M.; Yin, B. Smart factory of industry 4.0: Key technologies, application case, and challenges. IEEE Access 2017, 6, 6505-6519. [CrossRef]

5. Qin, J.; Liu, Y.; Grosvenor, R. A categorical framework of manufacturing for industry 4.0 and beyond. Procedia Cirp 2016, 52, 173-178. [CrossRef]

6. Tao, F; Qi, Q. New IT driven service-oriented smart manufacturing: Framework and characteristics. IEEE Trans. Syst. Man Cybern. Syst. 2017, 49, 81-91. [CrossRef]

7. Negri, E.; Fumagalli, L.; Macchi, M. A review of the roles of digital twin in CPS-based production systems. Procedia. Manuf. 2017, 11, 939-948. [CrossRef] 
8. Thombansen, U.; Schuttler, J.; Auerbach, T.; Beckers, M.; Buchholz, G.; Eppelt, U.; Gloy, Y.; Fritz, P.; Kratz, S.; Lose, J.; et al. Model-based self-optimization for manufacturing systems. In Proceedings of the 17th International Conference on Con-current Enterprising (ICE), Aachen, Germany, 20-22 June 2011; pp. 1-9.

9. Perales, D.P.; Valero, F.A.; García, A.B. Industry 4.0: A classification scheme. In Closing the Gap between Practice and Research in Industrial Engineering; Viles, E., Ormazábal, M., Lleó, A., Eds.; Springer: Berlin/Heidelberg, Germany, 2018; pp. 343-350.

10. Magnanini, M.C.; Tolio, T.A. A model-based Digital Twin to support responsive manufacturing systems. Cirp Ann. 2021, 70, 353-356. [CrossRef]

11. Rouhani, A.; Fazelhashemi, S. Forget about TPM, 1st ed.; Rasa Cultural Services Institute: Tehran, Iran, 2009.

12. Al-Ahmari, A.M.A.; Ridgway, K. An integrated modelling method to support manufacturing systems analysis and design. Comput. Ind. 1999, 38, 225-238. [CrossRef]

13. Oztemel, E.; Gursev, S. Literature review of Industry 4.0 and related technologies. J. Intell. Manuf. 2020, 31, 127-182. [CrossRef]

14. Scheer, A.W. Industrie 4.0: Wie Sehen Produktionsprozesse im Jahr 2020 Aus; IMC AG: Saarbrücken, Germany, 2013.

15. Stock, T.; Seliger, G. Opportunities of sustainable manufacturing in industry 4.0. Procedia Cirp 2016, 40, 536-541. [CrossRef]

16. Dhilon, B.S. Maintainability, Maintenance and Reliability for Engineers; Taylor and Francis: Boca Raton, FL, USA, 2006.

17. DIN, E. 13306: Instandhaltung-Begriffe der Instandhaltung; Maintenance Terminology: Berlin, Germany, 2010.

18. Mourtzis, D.; Angelopoulos, J.; Boli, N. Maintenance assistance application of Engineering to Order manufacturing equipment: A Product Service System (PSS) approach. IFAC-PapersOnLine 2018, 51, 217-222. [CrossRef]

19. Ben-Daya, M.; Duffuaa, S.O.; Raouf, A.; Knezevic, J.; Ait-Kadi, D. Handbook of Maintenance Management and Engineering; Springer: London, UK, 2009; Volume 7.

20. Mcadam, R.; Duffner, A. Implementation of total productive maintenance in support of an established total quality pro-gramme Total Qual. Manag. 1996, 7, 613-630. [CrossRef]

21. Matyas, K. Instandhaltungslogistik: Qualität und Produktivität Steigern, 5th ed.; Carl Hanser Verlag: München, Germany, 2013.

22. Pawellek, I.G. Planung der Instandhaltung. Integrierte Instandhaltung und Ersatzteillogistik; Springer: Berlin/Heidelberg, Germany, 2013.

23. Voigt, K.I.; Steinmann, D.I.F.; Bauer, D.I.J.; Dremel, A. Condition Monitoring Als Schlüsseltechnologie-Eine Analyse Der Anforderungen an Neue Geschäftsmodelle Für Den Remote Service; Heinz Nixdorf Institut-Universität Paderborn: Paderborn, Germany, 2013.

24. Herterich, M.M.; Uebernickel, F.; Brenner, W. The impact of cyber-physical systems on industrial services in manufacturing. Procedia Cirp 2015, 30, 323-328. [CrossRef]

25. Ivanov, D.; Sokolov, B.V. Adaptive Supply Chain Management; Springer: London, UK, 2010.

26. Chopra, S.; Meindl, P. Supply Chain Management. Strategy, Planning, and Operation; Springer: Berlin/Heidelberg, Germany, 2007.

27. Baumgarten, H. Das Beste der Logistik. Innovationen, Strategien, Umsetzungen; Springer: Berlin/Heidelberg, Germany, 2008.

28. Schuh, G.; Stich, V. Logistikmanagement, 2nd ed.; Springer Vieweg: Berlin, Germany, 2013.

29. Lummus, R.; Duclos, K.; Vokurka, J. Supply Chain Flexibility: Building a New Model. Glob. J. Flex. Syst. Manag. 2003, 4, 1-13.

30. Kakouris, A.; Polychronopoulos, G. Enterprise resource planning (ERP) system: An effective tool for production management. Manag. Res. News 2005, 28, 66-78. [CrossRef]

31. Zäpfel, G. Grundzüge des Produktions-und Logistikmanagement; Walter de Gruyter: München, Germany, 2001.

32. Hackstein, R. Produktionsplanung und-Steuerung (PPS): Ein Handbuch Für Die Betriebspraxis; VDI-Verlag: Düsseldorf, Germany, 1984.

33. Schuh, G.; Brosze, T.; Brandenburg, U.; Cuber, S.; Schenk, M.; Quick, J.; Schmidt, C.; Helmig, J.; Schürmeyer, M.; Hering, N. Grundlagen der produktionsplanung und-steuerung. Prod. Steuer. 2012, 1, 9-293.

34. Stotz, H. 8600 Unternehmen Gaben Auskunft. Comput. Prod. 2001, 2, 32.

35. Kirby, C.; Brosa, N. La Logística Como Factor De Competitividad De Las Pymes En Las Américas; Banco I nteramericano de Desarrollo: Santo Domingo, Republica Dominicana, 2011.

36. Muñoz Bosch, M. ERP Para La Pequeña Empresa; Universitat Politècnica de Catalunya: Barcelona, Spain, 2008.

37. Schilberg, D.; Meisen, T.; Reinhard, R. Virtual Production-The connection of the modules through the Virtual Production Intelligence. In Proceedings of the World Congress on Engineering and Computer Science 2013, San Francisco, CA, USA, 23-25 October 2013; Volume 2, pp. 23-25.

38. Mittal, S.; Khan, M.A.; Romero, D.; Wuest, T. Smart manufacturing: Characteristics, technologies and enabling factors. J. Eng. Manuf. 2019, 233, 1342-1361. [CrossRef]

39. Reggelin, T. Schneller Entscheiden. Log.Kompass; DVV Media Group: Hamburg, Germany, 2012; p. 5.

40. Habchi, G.; Berchet, C. A model for manufacturing systems simulation with a control dimension. Simul. Model. Pract. Theory 2003, 11, 21-44. [CrossRef]

41. Borshchev, A. Simulation Modeling with AnyLogic: Agent Based, Discrete Event and System Dynamics Methods; DVV Media Group: Hamburg, Germany, 2013; pp. 225-269.

42. Florescu, A.; Barabas, S.A. Modeling and simulation of a flexible manufacturing system-A basic component of industry 4.0. Appl. Sci. 2020, 10, 8300. [CrossRef]

43. Campuzano, F.; Bru, J.M. Supply Chain Simulation: A System Dynamics Approach for Improving Performance; Springer Science \& Business Media: Berlin/Heidelberg, Germany, 2011.

44. Siestrup, G.; Zeeb, D. Reifegradbestimmung: Der Weg Zur Supply Chain 4.0; Hochschule Furtwangen: Villingen-Schwenningen, Germany, 2017.

45. McCormick, D.W.; Spee, J.C. IBM and Germany 1922-1941. Organ. Manag. J. 2008, 5, 214-223. [CrossRef] 
46. Gallego-García, S.; Reschke, J.; García-García, M. Design and simulation of a capacity management model using a digital twin approach based on the viable system model: Case study of an automotive plant. Appl. Sci. 2019, 9, 5567. [CrossRef]

47. Auerbach, T.; Bauhoff, F.; Beckers, M.; Behnen, D.; Brecher, C.; Brosze, T.; Esser, M. Selbstoptimierende produktionssysteme. In Integrative Produktionstechnik Für Hochlohnländer; Springer: Berlin, Germany, 2011; pp. 747-1057.

48. Mayer, M.P. Entwicklung Eines Kognitionsergonomischen Konzeptes und Eines Simulationssystems Für die Robotergestützte Montage; Shaker: Aachen, Germany, 2012.

49. Hinckeldeyn, J.; Dekkers, R.; Altfeld, N.; Kreutzfeldt, J. Bottleneck-based synchronisation of engineering and manufacturing. In Proceedings of the International Association for Management of Technology IAMOT 2010 Proceedings of the 19th International Conference on Management of Technology, Cairo, Egypt, 8-11 March 2010. 